\title{
Erratum to: Analyzing the effect of dynamically assigned treatments using duration models, binary treatment models, and panel data models
}

\section{Jaap H. Abbring1 • Gerard J. van den Berg ${ }^{2}$}

\section{Erratum to: Empirical Economics (2004) 29:5-20 DOI 10.1007/s00181-003-0188-y}

The first displayed (unnumbered) equation on page 11 in Abbring and van den Berg (2004) gives an expression for $\operatorname{Pr}\left(T_{m}>t, T_{p}>t_{p} \mid x\right)$ that is incorrect. Under the assumption (implicit in the paper) that the distribution of $T_{p} \mid x$ is not defective,

$$
\operatorname{Pr}\left(T_{m}>t, T_{p}>t_{p} \mid x\right)=\int_{t_{p}}^{\infty} \frac{\partial \operatorname{Pr}\left(T_{m}>t, T_{p} \leq u \mid x\right)}{\partial u} d u
$$

with

$$
\begin{aligned}
& \frac{\partial \operatorname{Pr}\left(T_{m}>t, T_{p} \leq t_{p} \mid x\right)}{\partial t_{p}} \\
& \quad=\int_{0}^{\infty} \int_{0}^{\infty} \exp \left(-\phi_{m}(x) v_{m}\left[\Lambda_{m}\left(\min \left\{t, t_{p}\right\}\right)+\mathrm{I}\left(t>t_{p}\right) \Delta\left(t \mid t_{p}, x\right)\right]\right) \\
& \quad \times \phi_{p}(x) v_{p} \lambda_{p}\left(t_{p}\right) \exp \left(-\phi_{p}(x) v_{p} \Lambda_{p}\left(t_{p}\right)\right) d G\left(v_{m}, v_{p}\right) .
\end{aligned}
$$

The online version of the original article can be found under https://doi.org/10.1007/s00181-003-0188-y.

Jaap H. Abbring

jaap@abbring.org

Gerard J. van den Berg

gjvdberg@xs4all.nl

1 CentER, Department of Econometrics and Operations Research, Tilburg University, P.O. Box 90153, 5000 LE Tilburg, The Netherlands

2 Department of Economics, University of Bristol, Bristol, UK 
If $t_{p} \geq t$, this does not depend on the treatment effect $\Delta\left(t \mid t_{p}, x\right)$ and gives the expression on page 11 . If $t_{p}<t$, however, the expression on page 11 is incorrect. This is an isolated and inconsequential error in the sense that the equation is not referred to elsewhere in the paper and does not affect the text. We are grateful to Sumedha Gupta for drawing our attention to this error (first online draft of this erratum dated 2011).

The affiliation of the authors have also been updated and provided in the erratum.

\section{Reference}

Abbring JH, van den Berg GJ (2004) Analyzing the effect of dynamically assigned treatments using duration models, binary treatment models, and panel data models. Empir Econ 29:5-20 